\title{
LAKON PERJALANAN KE BARAT EPISODE SUN GO KONG DI NEGERI KALINGGA DALAM OPERA CINA SANGGAR MEKAR TERATAI SEMARANG
}

\author{
Afifah Emi Nuzulia \\ Institut Seni Indonesia Yogyakarta \\ afifah.emi129@gmail.com
}

\begin{abstract}
Abstrak: Opera Cina merupakan hiburan populer yang mengadaptasi legenda dan mitos Tionghoa ke dalam bentuk pertunjukan. Opera ini disebarkan dan dipentaskan di berbagai negara, salah satunya di Semarang, Indonesia, oleh Sanggar Mekar Teratai. Sanggar ini mementaskan Opera Cina berjudul Sun Go Kong di Negeri Kalingga sebagai wujud akulturasi kebudayaan masyarakat Tionghoa dengan masyarakat setempat. Melalui metode Kernodle, akan dijabarkan tiga tahapan pementasan teater dengan hasil akhir berupa kritik terhadap unsurunsur Opera Cina ini.
\end{abstract}

Kata kunci: Opera Cina, legenda dan mitos Tionghoa, akulturasi, Semarang, Sanggar Mekar Teratai

\begin{abstract}
Chinese Opera is a popular entertainment that adapts Chinese legends and myths for performances. This opera is spread and performed in various countries, one of them being in Semarang, Indonesia, by Sanggar Mekar Teratai. This studio performs a Chinese Opera titled Sun Go Kong di Negeri Kalingga (Sun Go Kong in Country of Kalingga) as a form of acculturation between the Chinese and the local's culture. Through Kernodle's method, it shall be discussed on how a theatre should be prepared in three stages with the final result as a critic against this Chinese Opera's elements.
\end{abstract}

Key words: Performance, Chinese opera, Chinese legend and myth, acculturation, Semarang, Sanggar Mekar Teratai.

\section{Pendahuluan}

Semarang merupakan salah satu jalur perdagangan yang disinggahi oleh kapalkapal pedagang bangsa asing. Pedagangpedagang dari berbagai bangsa, seperti Bangsa Persia, India, Timur Tengah, Tiongkok bahkan Bangsa Eropa datang untuk mencari rempah-rempah dan hasil bumi lainnya. Interaksi perdagangan secara tidak langsung memberikan andil besar terhadap masuknya kebudayaan asing. Para pedagang asing tentunya membawa kebudayaan serta kebiasaan-kebiasaan dari masing-masing bangsanya. Beberapa dari mereka memutuskan untuk menetap dan tidak sedikit yang akhirnya menikah dengan penduduk lokal (pribumi).

Perkawinan dan lingkungan hidup yang berdampingan melahirkan kebudayaan gabungan antar berbagai kebudayaan yang ada. Penggabungan unsur-unsur dari dua atau lebih kebudayaan berbeda yang pada dasarnya akan melahirkan kebudayaan multikultural.

"The Columbia Electronic Encyclopedia defines multiculturalism or cultural pluralism as a term describing the coexistence of many cultures in a locality, without any one culture dominating the region. By making the broadest range of human differences acceptable to the largest number of 
people, multiculturalism seeks to overcome racism, sexism, and other forms of discrimination."

(Ensiklopedia Elektronik Kolumbia mendefinisikan multikultural atau kebudayaan plural sebagai sebuah bentuk yang menjelaskan tentang keberadaan bermacam-macam kebudayaan dalam sebuah lokalitas, tanpa adanya satu kebudayaan yang mendominasi wilayah tersebut. Dengan membuat rentang perbedaan manusia yang paling luas dapat diterima oleh jumlah orang terbesar, multikultural berusaha mengatasi rasisme, seksisme, dan bentuk diskriminasi lainnya) (Anggraeni, 2011).

Berdasarkan kutipan diatas jelas yang dimaksud multikultural atau kebudayaan plural adalah sebuah bentuk penjelasan tentang keberadaan beragam budaya dalam sebuah lokalitas, tanpa ada yang mendominasi. Guna mengatasi perbedaan manusia yang paling luas dapat diterima masyarakat mayoritas, multikulturalisme berusaha untuk mengatasi rasisme, sexsisme serta bentuk-bentuk deskriminasi lainnya.

Multikultural di Kota Semarang tidak hanya berhenti pada kesenian-kesenian tradisi, namun tetap berlanjut pada keseniankesenian sekarang ini. Sanggar Mekar Teratai Semarang merupakan salah satu sanggar yang turut menampilkan kesenian hasil kolaborasi antarbudaya. Melalui pertunjukkan Opera Cina, Sanggar Mekar Teratai Semarang menampilkan perpaduan budaya Tionghoa dan Jawa dalam pertunjukannya, yang tentunya membuat Opera Cina Sanggar Mekar Teratai Semarang memiliki perbedaan dengan Opera Cina dari daratan Tiongkok. Di Indonesia terdapat beberapa sanggar atau kelompok yang masih aktif menghidupkan Opera Cina, salah satunya Sanggar Mekar Teratai Semarang ini yang berada di Kota Semarang.
Kemampuan berubah merupakan sifat penting dalam kebudayaan manusia. Tanpa perubahan, kebudayaan tidak mampu menyesuaikan diri dengan keadaan yang senantiasa berubah (Haviland, 1988). Sebagai sebuah karya multikultural, tidak hanya unsur-unsur budaya Tionghoa yang membentuk pertunjukkan tersebut. Unsurunsur budaya Jawa dan isu-isu yang hidup ditengah-tengah masyarakat kota Semarang turut memberikan kontribusi dalam pembentukan pertunjukkan Opera Cina Sanggar Mekar Teratai Semarang tersebut.

\section{Kesenian Opera Cina Sanggar Mekar Teratai Semarang}

Opera Cina sendiri merupakan sebuah pertunjukan yang menggabungkan unsur-unsur sastra, puisi, dialog, tarian, musik, akrobatik dan seni bela diri. Opera Cina pada awalnya hanya kumpulan lagu dan tarian rakyat yang digunakan untuk kepentingan upacara ritual. Berkembangnya jaman, Opera Cina menambahkan unsur drama, musikal, akrobatik dan ilmu bela diri (Lim, 2011). Sanggar Mekar Teratai mengadaptasi gaya permainan Opera Beijing. Dengan adanya penambahan unsurunsur budaya Jawa dan isu-isu yang beredar kedalam bentuk pertunjukkan, maka dapat dikatakan Opera Cina Sanggar Mekar Teratai Semarang ini tidak sepenuhnya memakai konvensi-konvensi yang terdapat dalam gaya maupun bentuk permainan Opera Beijing. Diawal karir operanya, Sanggar Mekar Teratai Semarang hanya menampilkan Opera Cina dengan membawakan cerita-cerita klasik Sam Kok yang diubah ke dalam bahasa Indonesia. Selain cerita klasik Sam Kok, mereka mulai mengangkat cerita-cerita legenda bangsa Tionghoa.

Pada kesempatan kali ini, kisah yang dibahas yaitu Sun Go Kong Di Negeri Kalingga. kisah tersebut merupakan salah satu kisah dalam rangkaian kisah-kisah 
Perjalanan Ke Barat. Seperti yang telah diketahui secara luas, rombongan Pendeta Tong melakukan perjalanan dari daratan Tiongkok menuju ke Barat (India) untuk mendapatkan Kitab Suci Buddha. Disebutkan dalam rangkaian novel Xi You $J i$, memang benar adanya bahwa Pendeta Tong beserta rombongan mendapatkan banyak ujian dan rintangan, salah satunya ujian godaan nafsu duniawi yaitu harta dan wanita. Dewi Kwan Im beserta para Boddhisatva sampai turun ke dunia manusia untuk menguji secara langsung keimanan Pendeta Tong dan ketiga muridnya. Akan tetapi tidak pernah disebutkan bahwa mereka singgah ke suatu daerah atau kerajaan bernama Kalingga, baik dalam novel Xi You Ji maupun Sejarah perjalanan Pendeta Tong.

Menurut sejarah kerajaan di Indonesia, Kerajaan Kalingga berada di pesisir utara pulau Jawa, kemungkinan berada disuatu tempat antara Kabupaten Pekalongan dan Kabupaten Jepara sekarang (Raharta, 2013). Kerajaan bercorak HinduBuddha tersebut dipimpin oleh seorang Raja yang sangat adil bernama Ratu Shima. Kerajaan Kalingga sendiri merupakan pusat agama Buddha di pulau Jawa pada abad ke7 Masehi. Ajaran Buddha Hinayana merupakan agama Buddha yang mengalami perkembangan pesat pada masa itu. Berdasarkan sumber-sumber notulen Tiongkok, pada tahun 664 Kerajaan Kalingga kedatangan seorang Pendeta Buddha dari Tiongkok, Hwi Ning. Tujuannya tidak lain adalah untuk menerjemahkan naskah terkenal agama Buddha Hinayana dari Bahasa Sanskerta kedalam Bahasa Cina. Kerajaan Kalingga sendiri mendapat sebutan Kerajaan Ho Ling oleh para pedagang Tiongkok yang datang.

Sardono W.S selaku penulis karya saduran Sun Go Kong di Negeri Kalingga memang sengaja menggabungkan kisah Pendeta Tong dengan Pendeta Hwi Ning yang memiliki kesamaan tujuan yaitu mencari Kitab Suci Buddha. Perbedaannya dalam kisah kedua pendeta tersebut adalah latar tempat terjadinya peristiwa. Pendeta Tong melakukan perjalanan ke India sedangkan Pendeta Hwi Ning mencari Kitab Suci sampai ke Nusantara. Penggambaran proses tawar-menawar kebudayaan dalam saduran tersebut, mampu memikat tim kreatif Sanggar Mekar Teratai untuk membawakan lakon tersebut. Melalui lakon ini, proses akulturasi Bangsa Indonesia pada masa sekarang dikritisi secara terangterangan. Bangsa pendatang dan Bangsa Pribumi harusnya mampu bertoleransi satu sama lain melalui uluran tangan budaya dan adat-istiadat yang ada menjadi satu bangsa kesatuan yaitu Bangsa Indonesia.

Sejak awal berdiri Sanggar Mekar Teratai Semarang terbuka untuk siapa saja yang berkeinginan berpartisipasi dalam keseniannya. Tidak ada batasan gender dan usia dalam anggotanya. Para anggota perempuan akan dilatih tarian klasik Tiongkok, sedangkan anggota laki-laki akan dilatih Taichi dan gerakan kungfu lainnya. Anggota Sanggar Mekar Teratai Semarang tidak dituntut untuk ikut dalam setiap pementasan yang dilakukan, hanya yang bersedia dan memenuhi kriteria tokoh yang ditunjuk. Dalam segi pemilihan pemain, pelatih akan menentukan siapa saja yang akan mendapatkan peran. Pemain yang dipilih ditentukan biasanya dari postur tubuh dan bentuk wajah tokoh yang akan diperankan. Anggota Sanggar Mekar Teratai Semarang aktif berlatih di aula Klenteng Tay Kak Sie Gg. Lombok Kota Semarang.

\section{Pertunjukan Opera Cina Lakon Perjalanan Ke Barat Episode Sun Go Kong di Negeri Kalingga}

Kernodle membagi tiga tahapan yang harus dilalui sebelum sebuah drama dapat dipentaskan di panggung, yaitu perencanaan, latihan, dan pertunjukan (Kernodle, 1967). 
Tahap pertama, perencanaan bertujuan untuk mewujudkan naskah dari penulis menjadi perencanaan yang utuh dari seorang sutradara. Pada bagian perencanaan terbagi atas bagian satu yaitu mengklarifikasi drama dalam hubungan drama dengan keseluruhan alat-alat kontrol, seperti jenis drama, keterangan pertunjukan dengan penikmat, konvensi, dan gaya. Bagian dua, menganalisis drama terhadap nilai-nilai struktur (alur, karakter, dan tema) dan tekstur (dialog, spectacle, dan suasana) (Kernodle, 1967).

\section{Analisis Struktur}

Alur adalah pengaturan seluruh peristiwa yang terjadi di atas panggung. Dengan kata lain alur merupakan pola dasar dari keseluruhan pola ritmis pertunjukan. ${ }^{6}$ Alur dalam drama dibagi menjadi babak-babak dan adegan-adegan. Alur cerita dibagi menjadi pengenalan, komplikasi, konflik, klimaks dan penyelesaian. Berikut tahapan alur

\section{a. Pengenalan}

Tahap pengenalan menggambarkan keadaan awal perjalanan Pendeta Tong menuju ke barat ditemani oleh ketiga muridnya. Dalam perjalanannya, mereka singgah ke sebuah negeri bernama Negeri Kalingga. Negeri Kalingga dikenal sebagai negeri yang subur dan makmur.

01. Narator : .... Pendeta Tong berempat melanjutkan perjalanan sampai di suatu tempat yang teramat asing. Rupanya mereka sampai di sebuah negeri bernama Kholiq atau Kalingga. Suatu negeri yang subur, makmur dan penduduknya sangat ramah. Mereka sepakat berganti pakaian menurut adat negeri itu dan mencari nama panggilan yang sesuai.

\section{b. Komplikasi}

Tahap komplikasi pada pementasan opera ini terlihat pada adegan dimana Dewi Lie Shen Sheng meminta Dewi Kwan Im untuk menguji keimanan Pendeta Tong dan muridnya, terutama Tie Pat Kay. Menurut Dewi Lie Shen Sheng, Pat Kay belum mampu melepas nafsu duniawi miliknya. Dewi Kwan Im pun menyetujui permintaan tersebut.

03. Shen Sheng: Aku lihat diantara ketiga murid Tong Sam Cong, Pat Kay ini paling bermasalah. Ia tampaknya belum lepas dari nafsu duniawi. Kita perlu menguji mereka. Bagaimana menurutmu?

04. Kwan Im: Betul. Aku juga melihat demikian. Mari lah kita uji mereka semua.

Saat Dewi Kwan Im dan para Bodhisatya telah menjelma menjadi Rondho Godho Dunyo serta tiga putrinya, mereka menggoda Pendeta Tong Beserta ketiga muridnya.

07. Rondo Ngodho: ....Kami tak mempunyai anak laki-laki, hanya perempuan 3 orang. Kami Hidup berkelimpahan namun kami berempat, ibu dan anak menginginkan suami yang bisa jadi andalan. Rupanya kalian berempat dikirim Sang Budha untuk menjadi jodoh kami. Kalau kalian berminat, kami dengan senang hati menerima.

Para putri Rondo Ngodho Dunya mulai menari di hadapan Pendeta Tong dan murid-muridnya. Pada adegan ini Tie Pat Kay mulai nampak tergoda akan kecantikan putri-putri Rondo Ngodho Dunya.

\section{c. Klimaks}

Awal klimaks dalam pertunjukan ini ditandai dengan Pat Kay yang mengendapendap masuk ke dalam rumah Rondo Ngodho Dunya untuk mencari para anak gadis Rondo.

08. Narator: Demalung mengikuti mencari nyonya rumah ke ruang belakang. Ia senang menemukan tiga gadis tersebut sedang bermain-main di taman.

Sesampainya Pat Kay di taman belakang rumah, dia mulai mendekati 
putri-putri Rondo Ngodho Dunya. Rondho yang mulai melihat perilaku Pat Kay terhadap putrinya, mulai mendekati Pat Kay. Rondo Ngodho Dunya bertanya manakah diantara ketiga putrinya yang akan diperistri olehnya. Pat Kay yang serakah menjawab dengan ringannya bahwa ia ingin menikahi semuanya termasuk Rondo Ngodho Dunya.

09. Narator : Sang nyonya lalu bertanya manakah dari antara anak gadisnya yang akan dipilih

10.Tie Pat Kay: Gimana kalau aku ambil semua, termasuk ibunya sekalian. (tertawa dengan suara seperti babi)

Puncak klimak ditampilkan pada adegan saat ketiga putri Rondo Ngodho Dunya menari mengelilingi Tie Pat Kay dengan menggunakan selendang. Tanpa sadar Pat Kay telah terikat kencang oleh selendang para anak gadis tersebut.

11. Narator : Nyonya lalu menyuruh ketiga putrinya menari dengan selendang. Siapa yang berhasil ditangkap, itulah jodoh bagi Demalung. Ketiga gadis itu mulai menari, lalu bergerak memutar. Balutan semakin kencang. Akhirnya Si Babi tak terkutik. Urisiswo terkekeh-kekeh melihat Demalung terikat kencang.

\section{d. Resolusi}

Pada tahap ini adegan tidak ditunjukkan menggunakan dialog melainkan dihadirkan dengan gerakan tokoh yang diiringi oleh musik. Masuk Sembilan penari membawakan tari seribu tangan, tarian tersebut digunakan sebagai transisi perubahan wujud Rondo Ngodho Dunya berserta tiga anak gadisnya kembali ke wujud semula sebagai Dewi Kwan Im dan para Boddhisatva.

\section{e. Penyelesaian \\ Perubahan wujud Dewi Kwan Im ke bentuk asal menandai pertunjukan ini telah memasuki tahap akhir, yaitu tahap}

penyelesaian. Adegan penyelesaian tersebut menampilkan Pat Kay yang telah menyadari kesalahannya.

13. Kwan Im: Tong Sam Cong, imanmu sangat teguh. Tak tergoda oleh kesenangan dunia. Pat Kay, kau harus belajar mengekang hawa nafsu dan keinginan duniawi. Perjalanan ke barat masih jauh. Cobaan masih panjang.

14. Pat Kay: Aku tak berani berkeinginan menjadi menantu lagi.

15. Narator : Tong Sam Cong, semua berlutut. Sang dewi dan para Bodhisatva lalu pergi. Kemudian pendeta Tong atau Sang Prajaka melanjutkan perjalanannya mengambil kitab suci ke langit barat.

Tema merupakan istilah lain yang digunakan untuk menyebut Premise suatu pertunjukan. Tema atau premis merupakan salah satu dari tiga bahan pokok pertunjukan disamping alur dan penokohan. Menurut Harymawan, tema atau premise adalah rumusan atau simpulan intisari cerita sebagai landasan ideal dalam menentukan arah tujuan cerita (Harymawan, 1993). Lakon Perjalanan Ke Barat episode Sun Go Kong di Negeri Kalingga ini mengangkat tentang ketetapan hati dan keteguhan iman dalam mengamalkan kebaikan-kebaikan dari Yang Maha Esa. Walau dalam proses perjalanannya banyak godaan serta rintangan yang menghalangi bahkan sampai membahayakan nyawa kita sebagai manusia biasa. Pertolongan Tuhan akan menyelamatkan kita. Seperti sikap tegas Pendeta Tong yang menolak secara halus permintaan Rondo Godho Dunyo untuk menikah. Diperkuat dengan dialog Dewi Kwan Im pada akhir pertunjukan

13. Kwan Im : Tong Sam Cong, imanmu sangat teguh. Tak tergoda oleh kesenangan dunia. Pat Kay, kau harus belajar mengekang hawa nafsu dan keinginan duniawi. Perjalanan ke barat masih jauh. Cobaan masih panjang. 


\section{Penciptaan Karakter}

Penciptaan setiap karakter tidak hanya bergantung pada usia, perawakan, pakaian, tempo, ritme, tetapi juga berdasar pada sikap karakteristik (characteristic attitude), peran dalam suatu masyarakat (role in society), sikap tokoh lain terhadapnya (compensations), Perubahan karakteristik (Spine to the character), Motivasi hidup tokoh (superego) (Harymawan, 1993).

a. Sun Go Kong (Sun Wu Kong / 孙悟空)

Sebagai seorang Raja kera, Go Kong tidak ingin menuruti perintah siapapun. Sebenarnya Go Kong sangat peduli dengan keselamatan pendeta Tong serta kedua adik seperguruannya. Ia sangat dapat diandalkan dalam memusnahkan musuh-musuhnya namun ia sering bertindak sesuai keinginan hatinya tanpa memikirkan orang lain. Dewi Kwan Im memberikan gelang kepala emas di kepala Go Kong. Hal itu dilakukan agar Go Kong mengikuti perintah pendeta Tong. Setiap kali Go Kong bertindak diluar kendali, maka pendeta Tong akan membacakan mantra yang akan membuat Go Kong mengalami sakit kepala yang luar biasa. Tokoh Go Kong dalam kisah Perjalanan Ke Barat adalah simbol atas sifat sombong, congkak, dan keras kepala dalam diri manusia.

b. Pendeta Tong Sam Cong (Tang San Zang / 唐三藏)

Pendeta Tong memiliki watak yang tegas, hal tersebut terlihat dari perilaku ketiga muridnya yang selalu patuh dengan perkataan dan keinginan Pendeta Tong. Sosok setengah baya yang memiliki pandangan yang bijak diwujudkan dengan tutur kata yang halus. Berkat kehalusan perilaku dan tutur katanya, Pendeta Tong dapat dengan mudah diterima oleh orang lain. Keteguhan Iman dan berpendirian teguh tokoh Pendeta Tong ditunjukkan pada saat Adegan Rondo Ngodho Dunya mulai merayunya melalui gimmick penolakan. Pendeta Tong sangat berwelas asih kepada semua makhluk hidup terutama wanita dan anak-anak, oleh sebab itu Pendeta Tong senantiasa tidak mampu melihat wanita dan anak-anak menderita.

c. Tie Pat Kay (Zhu Ba jie / 猪八戒)

Setelah menjadi siluman babi, Pat Kay menjadi serakah, rakus dan mudah tergoda oleh perempuan. Sifat duniawi tersebut sering menimbulkan masalah baik untuk dirinya sendiri maupun bagi Pendeta Tong dan saudara seperguruannya. Melalui sosok Pat Kay, Wu Cheng En ingin menggambarkan sifat keserakahan dan tidak dapat mengendalikan nafsu duniawi pada setiap manusia. Dalam episode ini diceritakan bahwa akibat sifat buruk Pat Kay, Pendeta Tong berserta rombongan mendapatkan cobaan dari para Boddhisatva.

d. Sa Ceng (Sha Wujing / 沙悟浄)

Ia Merupakan jelmaan dari siluman air. Sa Ceng menjadi adik ketiga karena dianggap paling lemah diantara ketiga murid Pendeta Tong. Sa Ceng ditugaskan untuk merawat kuda putih tunggangan Pendeta Tong serta membawa seluruh perbekalan. $\mathrm{Sa}$ Ceng lebih pendiam dan penurut dibandingkan kedua kakak seperguruannya. Ia tidak pernah mengeluh walaupun sering dicurangi oleh Go Kong dan Pat Kay. Sa Ceng pun satu-satunya yang paling memahami keinginan Pendeta Tong. Kemunculan Sa Ceng dalam novel Xi You Ji merupakan bentuk sindiran terhadap kebodohan dan kecil hati yang ada dalam diri manusia.

e. Dewi Kwan Im (Guan Shi Yin Pu Sa / 觀 世音菩薩)

Sikap welas asih Dewi Kwan Im terlihat dalam adegan pengampunan dosa Pat Kay. karakter tritagonis selalu melekat dalam tokoh Dewi Kwan Im dalam lakon Perjalanan Ke Barat. Keberadaan Dewi Kwan Im menjadi kunci pertemuan antara Tong Sam Cong dengan ketiga muridnya. 
Selama periode Perjalanan Ke Barat, Dewi Kwan Im dipercaya Sang Buddha sebagai pemandu serta penolong rombongan Pendeta Tong. Pada Pementasan episode kali ini pun, Dewi Kwan Im berperan sebagai penengah masalah.

f. Rondo Ngodho Dunya dan Tiga Putri

Sosok manusia hasil jelmaan Dewi

Kwan Im dan tiga Boddhisatva. Memiliki paras yang cantik, bentuk tubuh yang aduhai serta harta yang melimpah menjadi senjata ampuh untuk memikat nafsu duniawi setiap lelaki yang melihatnya. Terlebih ketika mengetahui bahwa tidak ada seorangpun sosok pria dalam rumah mereka. Perwujudan yang sedemikian sempurna merupakan simbol untuk mewakili eksistensi nafsu setiap manusia yang selalu berkecambuk dalam dirinya. Nafsu duniawi yang tidak mengenal jenis kelamin, usia, pendidikan, pekerjaan bahkan status sosial umat manusia. Jika ditarik dalam skala yang lebih besar, dalam kehidupan sosial bermasyarakat misalnya. Kesombongan serta rasa ingin menguasai yang lain tentunya akan menghambat proses persatuan dan kesatuan dalam masyarakat.

\section{Analisis Tekstur}

Pada adegan pembuka ini para pemain tidak melakukan dialog. Mereka menggantinya dengan gesture-gesture tubuh yang di perbesar, sebagai penguat narasi pengenalan yang dibacakan oleh Narator. Pat kay memberikan sinyal kelaparan dengan memegangi perutnya. Go Kong mencari buah yang dapat dimakan dengan gerakan seolah-olah sedang memanjat pohon. Pendeta Tong dan $\mathrm{Sa}$ Ceng yang seolah kagum dengan pemandangan di tempat-tempat yang baru mereka kunjungi.

Iringan musik instrumental guzheng sejak permulaan adegan menginformasikan bahwa para tokoh dalam lakon ini berasal dari daratan Tiongkok. Hal ini berbanding lurus dengan kostum yang dikenakan.
Penggabungan antara kostum yang dikenakan, musik yang dimainkan serta latar pemandangan pada layar LED mampu membentuk satu kesatuan pertanda yang utuh. Sehingga penonton dapat dengan mudah memahami bahwa lakon yang ditampilkan merupakan cerita asal Tiongkok. Komposisi pengunaan warna pada pencahayaan pada adegan pertama ini mampu menghidupkan perhatian penonton. hal tersebut dibuktikan dengan teriakan maupun suara tertawa saat para tokoh tersorot cahaya panggung.

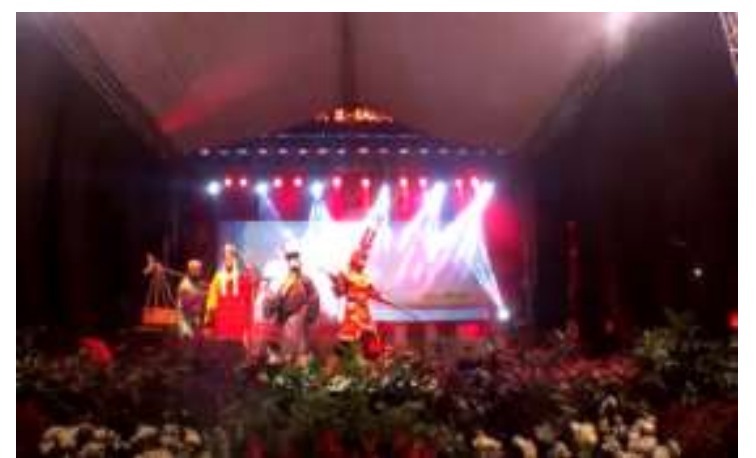

Gambar 1. Pendeta Tong dan murid-murid sedang melakukan perjalanan ke barat.

(Foto: Afifah, 2017)

Layar monitor di sisi belakang menampilkan gambar danau yang dipenuhi bunga teratai berwarna putih kemerahmudaan. Bunga Teratai merupakan simbol kemuliaan. Pemahaman tersebut secara turun-temurun menjadi kepercayaan masyarakat Tionghoa. Sang Buddha serta Dewi Kwan Im dalam banyak penggambarannya sedang dalam posisi berdiri maupun duduk diatas bunga teratai. Maka skeneri bunga teratai digunakan untuk mewakili latar kahyangan tempat para dewadewi berada. Warna merah muda pada kelopak bunga teratai merupakan jenis warna yang digunakan untuk merujuk pada sifat welas asih Dewi Kwan Im.

Gerakan pada tarian Seribu Tangan yang ditampilkan, bisa dikatakan terinspirasi dari salah satu keagungan Sang Buddha. Sang Buddha dipercaya mampu 
menggerakkan telapak tangannya dengan cepat, seolah-olah terlihat Ia memiliki seribu telapak tangan. gerakan-gerakan dalam tarian tersebut mampu ditampilkan dengan apik oleh para penari. Kecepatan dan ketepatan tangan para penari menjadi faktor penting dalam tarian ini. Bila salah satu penari melakukan kesalahan, maka efek canon pada tarian tersebut akan berantakan. Musik instrument yang digunakan sebagai pengiring adalah musik bergaya oriental dengan nuansa relaxing. Musik ini dipilih karena mampu menonjolkan suara khas dari erhu.

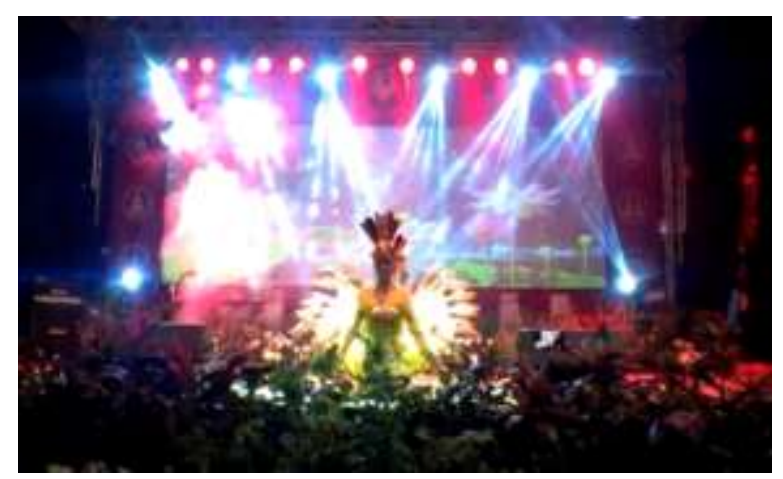

Gambar 2. Salah satu gerakan dalam tari

Seribu Tangan.

(Foto: Afifah, 2017)

Tidak banyak dialog yang dgunakan pada adegan ini. Mereka cenderung untuk langsung menyampaikan poin-poin dialog yang dianggap penting. Pemilihan nada pengucapannya kurang tepat, menyebabkan cara bicaranya terdengar seperti dibuat-buat. Sekali mendengar dialog antar pemain, penonton akan langsung mengetahui bahwa peertunjukan ini menggunakan metode lipsync. Mereka telah merekam dialog pembicaraan antar tokoh sebelumnya. Sehingga ketika di atas pangung mereka hanya perlu menggerakkan bibir dan menambahkan gerakan-gerakan tangan agar terlihat seolah mereka sedang berdialog secara langsung.

Salah satu spektakel dalam pertunjukan Sun Go Kong Di Negeri
Kalingga diwujudkan dengan pengunaan lagu permainan anak Gundul-gundul pacul dengan aransemen hip-hop. Adanya lagu tersebut ternyata mampu meningkatkan antusiasme penonton. Pendeta Tong beserta muridnya turut berjoget dalam alunan lagu.

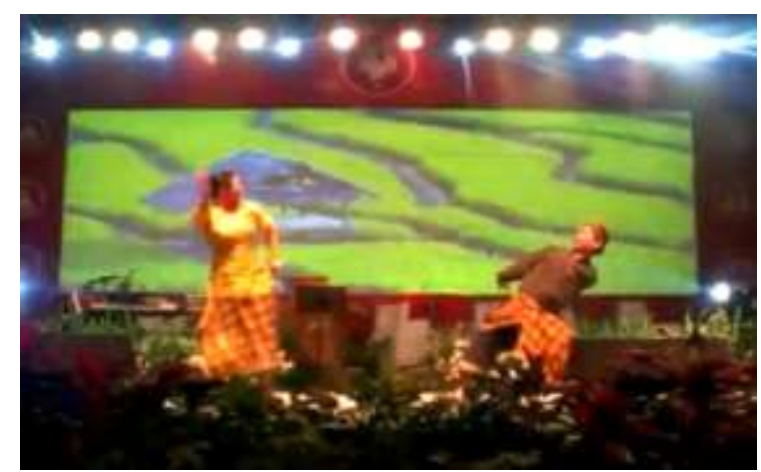

Gambar 3. Dua Penari masuk diiringi lagu Gundul-Gundul Pacul.

(Foto: Afifah, 2017)

Tarian Seribu Tangan pada adegan ending dibawakan secara rapi dan elegan. Walaupun dibawakan secara canon, tampaknya tidak mendatangkan masalah dalam perform mereka. Kekompakan antar penari dan ketepatan tempo menjadi kunci utama keberhasilan tarian Seribu Tangan. Namun disayangkan bahwa tarian yang anggun tersebut tidak mendapatkan perhatian yang sepantasnya. Pemakaian lampu dan filter yang tidak bijaksana membuat fokus pada adegan ini menjadi kabur. Penggunaan cahaya seharusnya hanya difokuskan pada penari, agar saat ada pergantian Rondo Ngodho Dunya dan ketiga putrinya berubah wujud menjadi Dewi Kwan Im dan para Boddhisatva tidak terlihat mencolok dan terkesan "kotor" di atas panggung. Pemberian sorot lampu tambahan dari depan dan samping panggung akan membantu memerikan fokus pada gerakan tangan para penari. Sorot lampu yang hanya datang dari lampu-lampu bagian belakang kurang memberikan kesan keagungan pada tarian seribu tangan tersebut. 


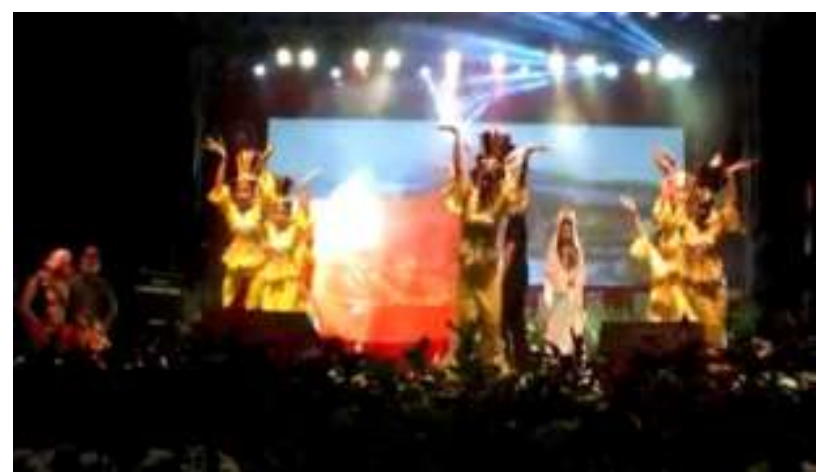

Gambar 4. Metode transisi yang digunakan saat Rondo Godho Dunyo dan tiga putrinya berubah kembali ke wujud asli mereka.

(Foto: Afifah, 2017)

\section{Simpulan}

Berdasarkan hasil pengamatan dan pengkajian analisis pertunjukan terhadap pementasan Opera Cina lakon Perjalanan Ke Barat episode Sun Go Kong Di Negeri Kalingga oleh Sanggar Mekar Teratai Semarang yang telah dijabarkan diatas, maka dapat ditarik kesimpulan bahwa: (1) Pertunjukan Opera Cina pada dasarnya tidak membutuhkan setting yang megah. Secara konvensional, Opera Cina hanya memerlukan satu meja dan dua kursi. Sebuah pertunjukkan Opera Cina konvensional, setting tersebut mampu menghadirkan suasana yang dibutuhkan. Namun pada pertunjukan milik Sanggar Mekar Teratai besifat lebih kontemporer. Episode Sun Go Kong Di Negeri Kalingga ini misalnya, dalam pertunjukannya telah menggunakan teknologi layar LCD untuk menampilkan latar tempat peristiwa. (2) Tata cahaya yang digunakan telah menggunakan lighting equipment yang modern. Penggunaan alat-alat pendukung yang lebih modern senyatanya lebih efektif dan efisien. (3) Tata busana pertunjukan milik Sanggar Mekar Teratai Semarang, tetap mempertahankan ciri-ciri busana setiap tokoh sesuai dengan aslinya. walaupun terdapat sedikit perbedaan dalam penggunaannya. Seperti bahan pakaian diganti dengan yang lebih ringan, warna pakaian disesuaikan dengan kebutuhan panggung. (4) Tata rias yang digunakan cenderung lebih sederhana dari Opera Cina pada umumnya. hal ini bertujuan untuk mempermudah penonton awam dalam menikmati pertunjukan. (5) Musik dalam pertunjukan opera hanya berfungsi sebagai pengiring tarian saja. namun gaya musik yang digunakan dalam pertunjukan Sun Go Kong Di Negeri Kalingga ini lebih beragam. tidak hanya musik bergaya oriental, musik popular jaman sekarang bahkan sampai tembang Jawa ikut andil dalam pertunjukannya. (6) Penyampaian dialog dilakukan secara lipsync. Hal tersebut terjadi karena para pemeran dalam pertunjukan tersebut tidak terbiasa berdialog secara dramatis. Mayoritas dari para pemain pada dasarnya tidak mengetahui tentang ilmu akting. Selama pertunjukan berlangsung para pemain hanya perlu untuk menggerakkan bibir sesuai dengan rekaman dialog yang diputar. (7) Tarian-tarian yang ditampilkan selama pementasan Sun Go Kong Di Negeri Kalingga ini menggunakan motif-motif yang lebih kontemporer. Gerakan-gerakan yang lebih luwes dan fleksibel, tanpa banyak aturan-aturan dalam menari layaknya tarian yang digunakan sebagai tari hiburan semata. (8) Blocking pemain dan pembagian panggung masih banyak yang tidak sesuai. Beberapa terjadi penumpukan posisi pemain dalam satu titik yang kurang enak dipandang mata. Sama halnya dengan penggunaan motif lantai yang kurang berani mengeksplor ruang pertunjukan. Hal tersebut terjadi karena sangat minimnya sumber daya manusia yang paham akan pengetahuan mengenai seni pertunjukan, khususnya drama atau teater.

\section{Daftar Pustaka}

Anggraeni, D. (2011). Does Multicultural Indonesia include its ethnic Chinese? Wacana, Jurnal Ilmu Pengetahuan Budaya; Multiculturalism. 139(2), 
256-278. Jakarta: Yayasan Pustaka Obor Indonesia.

Harymawan, RMA. (1993). Dramaturgi. Bandung: Remaja Rosdakarya Offset.

Haviland, W. A. (1988). Antropologi (R.G Sukardjo, Trans). Jakarta: Erlangga.

Kernodle, G. R. (1967). Invitation To The Theatre. USA: Harcourt, Brace \& world, inc.

Lim, SK. (2011). Origins of Chinese Opera; Asal Mula Opera China. Jakarta: Elex Media Komputindo.

Raharta, R. (2013). Sejarah Indonesia untuk SMA/MA/SMK/MAK Kelas X. Semester 1. Klaten: Intan Pariwara. 